\title{
Managerial Quotient: A Systematic Review among Managers of Tehran University of Medical Sciences
}

\author{
Dargahi Hossein ${ }^{*}$, Rahmani Hojjat², Bigdeli Zeinab33, Javadi Ghaleh Esmaeil4, \\ Yousefzadeh Negar ${ }^{5}$ \\ ${ }^{1}$ Health Care Management, School of Allied Medicine, Health Information Management Research Center, \\ Tehran University of Medical Sciences, Tehran, Iran \\ ${ }^{2}$ Health Care Management, School of Allied Medicine, Tehran University of Medical Sciences, Tehran, Iran \\ ${ }^{3}$ Health Care Management, School of Allied Medicine, Tehran University of Medical Sciences, Tehran, Iran \\ ${ }^{4}$ Health Care Management, School of Public Health Care Management, School of Public Health, Tehran \\ University of Medical Sciences, Tehran, Iran \\ ${ }^{5}$ Health Care Management, School of Public Health, Tehran University of Medical Sciences, Tehran, Iran \\ Email: "hdargahi@sina.tums.ac.ir
}

Received 7 November 2015; accepted 17 April 2016; published 22 April 2016

Copyright (C) 2016 by authors and Scientific Research Publishing Inc.

This work is licensed under the Creative Commons Attribution International License (CC BY). http://creativecommons.org/licenses/by/4.0/

(c) $\underset{\mathrm{EY}}{\text { (i) }}$ Open Access

\begin{abstract}
Among new managerial approach, usage of managerial quotient is very essential. Desired managerial quotient causes improvement of organizational productivity, performance and managerial skills. This systematic review article is aimed to introduce, explain and assess managerial quotient among the managers of Tehran University of Medical Sciences as the oldest and the best university in Iran. With paying attention to this research aim, related key words were determined, and library references and several search engines were used for choosing the research references from 1985 to 2015 and 733 references were studied, and finally 85 of them were selected. The research finding showed that Tehran University of Medical Sciences managers in hospitals, schools, and headquarters had desired managerial quotient. Also there was significant relationship between managerial with quotient transformational leadership, managerial art, morale consideration and creativity. Usage of hybrid managerial quotient in health care organizations is very essential. Therefore, it can be used for selection of the senior managers. Also, we suggest the managerial quotient courses should be taught to the health care management students in Iranian Universities of Medical Sciences, and training courses should be performed for Iranian health care system managers.
\end{abstract}

\section{Keywords}

Managerial Quotient, Managers, Tehran University of Medical Sciences

\footnotetext{
"Corresponding author.
}

How to cite this paper: Hossein, D., Hojjat, R., Zeinab, B., Esmaeil, J.G. and Negar, Y. (2016) Managerial Quotient: A Systematic Review among Managers of Tehran University of Medical Sciences. American Journal of Industrial and Business Management, 6, 467-479. http://dx.doi.org/10.4236/ajibm.2016.64043 


\section{Introduction}

Organizations, from the past until the present day, are looking for attaining advantages and the best position, in order to outrun from their rivals, and therefore, several methods of selecting and teaching human resource have been always introduced [1] (Amram, 2009). Replacing the word staffs with manpower, then with human resources, and finally with human capital shows the ascending trend in this viewpoint. Nowadays, this is a fact that managers as the most significant and influential position in every organization cannot be ignored [2] (Avolio et al., 2004). Managers are noticed from the selection and employment and then their training, knowledge, skills and work promotion are developed, and their development will be continued. The viewpoint of organization toward selecting efficient and appropriate managers has significantly changed over the past years, and somehow the priority has been given to intelligent individuals enjoying high capabilities [3] (Appelbaum et al., 2004).

Quotient is the mental ability, and it includes various capabilities, for example, deducing, planning, problem solving, thinking abstractedly, using language and learning [4] (Loehlin et al., 1996). There are different theories to present the dimensions and variety of quotient. Traditionally, quotient is defined based on the linguistic and logical-mathematical capabilities of the people. For the first time in the beginning of the $20^{\text {th }}$ century, Alfred Binet introduced Intelligence Quotient (IQ) to the world. He believed that mathematical intelligence guaranteed the effective learning, especially effective setting conceptual hierarchies, and removed unnecessary hierarchical system. Although, the psychologists have explained IQ as memory process and the recall system with most complexity [5] (American Psychological Association, 2015).

Gardner introduced a disputable theory about intelligence in which traditional opinions about intelligence quotient were challenged. Gardner established seven different types of knowledge to present a more comprehensive picture of intelligence which included linguistic-verbal, logical-mathematical, geometrical or spatial (forming a mental image of a fact, and its prompt, and easy change), musical (the ability to understand and create musical patterns), emotional, physical-kinetic (muscular abilities and proper kinetic movement), interpersonal (ability to understand others, motives and the type of interaction with each other), and finally intrapersonal intelligence (ability to understand yourself, to create self awareness of their nature and identity) [6] (Gardner \& Hatch, 1989).

Gardner believed that only paying attention to the first two types of knowledge ignored the other mental abilities, and the human capabilities have been partially taken into consideration [7] (Gardner \& Stough, 2002; [8] Gardner, 2006). Also, Sternberg basically changed the intelligence measurement in the same way and introduced a triple viewpoint with regard to intelligence:

- The ability to assess part by part,

- Experimental ability to think creatively, and to combine different separate experiences wisely,

- Contextual ability or is "the art of living in a city" which enables the individuals to play the game of environment management (others, situations, organizations, and contexts). He managed to create the tests in order to measure insight, problem solving, reasoning, creating vaster pictures of objects for people's success and establish of other life styles which were very crucial [9] (Sternberg et al., 2001).

Emotional Quotient (EQ) model was introduced for the first time in the beginning of 1990s, although EQ was named as Social Quotient in 1920, EQ has three levels: Abstract Intelligence (the ability and management of thinking), Mechanical Intelligence (real objects), and social quotient that implies to manage and understand of the people, and interact wisely with each other ([10] Bjorkquist \& Oystenman, 2000; [11] Crowne, 2009).

Goleman's Model in regard to Emotional Quotient (EQ) helps people to recognize their own emotions as well as others' emotions, and manage them with the best way, and interact to them. EQ motivate people to be successful sociable, and systematize their social relations. Therefore, Goleman introduced four dimensions of self awareness (having a deep insight of sentiments, emotions, weakness and strengths), self regulation (sentiments and emotions management), self motivation (being hopeful even when confronted with failure), and finally sympathy (recognizing people's emotional state and reacting well against them) ([12] Goleman, 1996; [13] Hedlund \& Sternberg, 2000).

Spiritual Quotient (SQ) was first introduced by Stevens in 1996, and then by Emmons in 1999. SQ combines spirituality and intelligence within a new structure and used for effective action and outcomes [14] (Criechton, 2008). SQ utilizes the spiritual capacities and resources for important decisions, and strives to solve daily problems. Hence, SQ combines spiritual mental subjects with outer assignments in the real world [15] (Zohar, 2005).

The concept of Spiritual Quotient includes adaptation, and problem solving behavior which is regarded as the 
highest level of cognitive, moral, emotional and interpersonal growth. New studies in neurology show that some brain actions are accompanied with spiritual experiences; therefore, spirituality has influences on several parts of the brain. Neurologists call these areas “God Zone”, since when they are artificially provoked, spiritual issues such as prayer, religious talks, sacrifice, dedication, humanism and etc. emerge [16] (Bennis \& Nenus 1985; [17] Bienstokh et al., 2003; [18] Boenke et al., 2003).

Wigglos Worth believes that SQ is the ability of compassionately, kindly, and wisely behaviors with internal and external calmness regardless of the situation [19] (Wiggles Woth, 2004). According to Emmons, SQ is the adaptive application of spiritual information in order to solve the problems in the daily life, and attain the goals of the life [20] (Emmons, 2001). Nobel believes that SQ is a innate aptitude of a human [21] (Nobel, 2008). Sisk and Torrance also declare that SQ is a deep self awareness in which humans are getting more and more familiar with their own dimensions. They believe that SQ is consisted of the following parts: internal knowledge (awareness of the internal nature, goodwill and unity with the world existence), deep intuition (people's unity and collaboration with each other), unity of human with the nature and the world (human concordance to the life process), and problem solving (recognizing the meaning, values, and the solution of the problems in a larger scale) [22] (Sisk \& Torrence, 2009).

Moral Intelligence was first introduced by Borba, who defines "as the ability to recognize the difference between right with wrong things, to have strong believes and behave honestly” [23] (Borba, 2005). Lennik \& Kiel state that moral intelligence is derived from four principles: honesty (coordination between individuals’ beliefs and performances), acceptance of responsibility (accepting the duties, and their outcomes, and accepting the mistakes and failures), compassion (attention to others), and forgiveness (awareness of shortcomings and mistakes as well as forgiving themselves and the others) [24] (Lennick \& Kiel, 2013).

Most of the humans' behaviors and performances are originated from moral principles and values [25] (Flite \& Harman, 2013). People, who have high moral intelligence, always join their performances with their morals, which enhance humans’ commitment, responsibilities, and improve individuals and team working efficiency. Utilization of moral intelligence can lead humans to recognize pains and discomforts of the others, listening fairly and comprehensively before judgment, acceptance of humans' diversities rejecting of immoral options, being sympathetic, fighting against injustice, and behaving respectfully towards others [26] (Mohammadi et al., 2013).

Cultural Intelligence is the ability of humans to response effectively when facing with humans who have different cultures which are divided into several levels. Cultural intelligence enables humans to recognize cultural differences carefully, and to follow logical behavior when confronting the other humans from different cultures. Using his experiences, a manager who enjoys a high level of cultural intelligence behaves in a way that is perfectly in accordance with the respective situation. People with high cultural intelligence capabilities are able to solve cultural challenges, and create cultural synergism [27] (Early \& Ang, 2003). They believe that cultural intelligence is the ability of a human to communicate successfully in new cultural environments which is usually different with his own culture. As they declare, a person who have the high ability of cultural intelligence, he or she is able to adapt himself with a new culture different from the one he was grown up in without losing his own cultural identity [28] (Ang et al., 2007).

Cultural intelligence is consisted of the following four factors: meta-cognitive factor (argumentation about inter-cultural experiences), cognitive (individuals' recognition about cultural similarities and differences), motivation (individuals' adaptation with a new culture), and finally behavior (the ability of a person to show verbal and non-verbal performances, interacting with the other people from various cultures) (Early \& Ang, 2003; Ang et al., 2007; [29] Van Driel 2008; [30] Mahjoob, 2004; [31] Chen \& Isa, 2003).

In the new approach to management, organizational culture, team work, and the managers' cooperation with others, play a significant role. Therefore, managers need specific behaviors in various positions to have more successful and effective performance. Managerial Quotient (MQ) is a collection of political, emotional and logical intelligence which cause the managers to behave effectively, including:

$$
\mathrm{MQ}=\mathrm{IQ}+\mathrm{EQ}+\mathrm{PQ}
$$

The managers with highly Political Quotient (PQ) don't have necessarily high IQ or EQ, but such managers traverse the way toward the top of the power pyramid faster in an organization. Political intelligence indicates people's ability to analyze impact of event, to create power resource, to use power, to create relationship with power holders, and finally to control and establishment of change management. In order to attain the organiza- 
tional goals, managers should know how to utilize the power resources, as well as how to use them [32] (Agha Sayed Hosseini, 2015).

Although, it is believed that IQ holds less value in comparison with MQ, EQ, and Body Quotient or BQ, but BQ is effective in humans' reactions, emotions, thoughts, self-confidence, and reliability determination. Appropriate nutrition, regular exercises, and adequate relaxation are considered significant factors in enhancing and keeping of this intelligence. IQ can only predict "the ability of logical reasoning" as well as "technical capabilities”, but it is not capable of forecasting managers' executive competency attain organizational success [33] (Jensen, 2012).

Owen announced that managerial quotient includes three factors; attaining the managerial abilities, team working, assessment of employees' performance, and help them to improve their abilities and skills, and finally recognizing the regulations in order to attain organizational success (Figure 1) [34] (Owen, 2006).

The new findings show that the performance of managers who enjoy higher work conscience and responsibility, but they lack EQ, are less successful in comparison with similar managers in other organizations, who have higher rate of EQ. It seems, premier managers have more cognitive capabilities and higher rate of EQ in comparison with the other managers whose performance are successful and excellent [35] (Sadeghi, 2015). New studies report that the managers, who can communicate with human resources effectively, will be pioneers in the future. Applying EQ among the managers is one of the factors that can play a significant role in their relationship with the employees of the organization [36] (Hosseini, 2015).

One of the most important ways of enhancing influence on the staff is the managers' power to be a change agent for attaining the organizational goal. For this reason, the managers need high political intelligence (PI). PI is considered as an active power levers in an organization. Managers can lead organizational changes using their high political intelligence [37] (Bourgeois \& Singh, 1985).

In new management approach, team working plays an important rate in an organization. According to this approach, the main focus addresses the employees' development to increase organizational productivity. Hence, managers who have social and communicative skills, they are good listener and speaker, and understand their own feelings as well as others, and can transfer their feelings to the employees. Managers with high political intelligence need to learn a wide range of political skills and knowledge which are considered as elements of political intelligence [38] (Treadway et al., 2005).

Recent studies within new century show that SQ, MQ, and cultural intelligence along with EQ, IQ and PI are considered as managerial intelligence. Therefore, this study is aimed to assess and specify managerial quotient among the managers of Tehran University of Medical Sciences (TUMS) as the best and oldest university in Iran as a systematic review. This university is the first number at Iranian scientific ranking and top 200 universities in the world ranking.

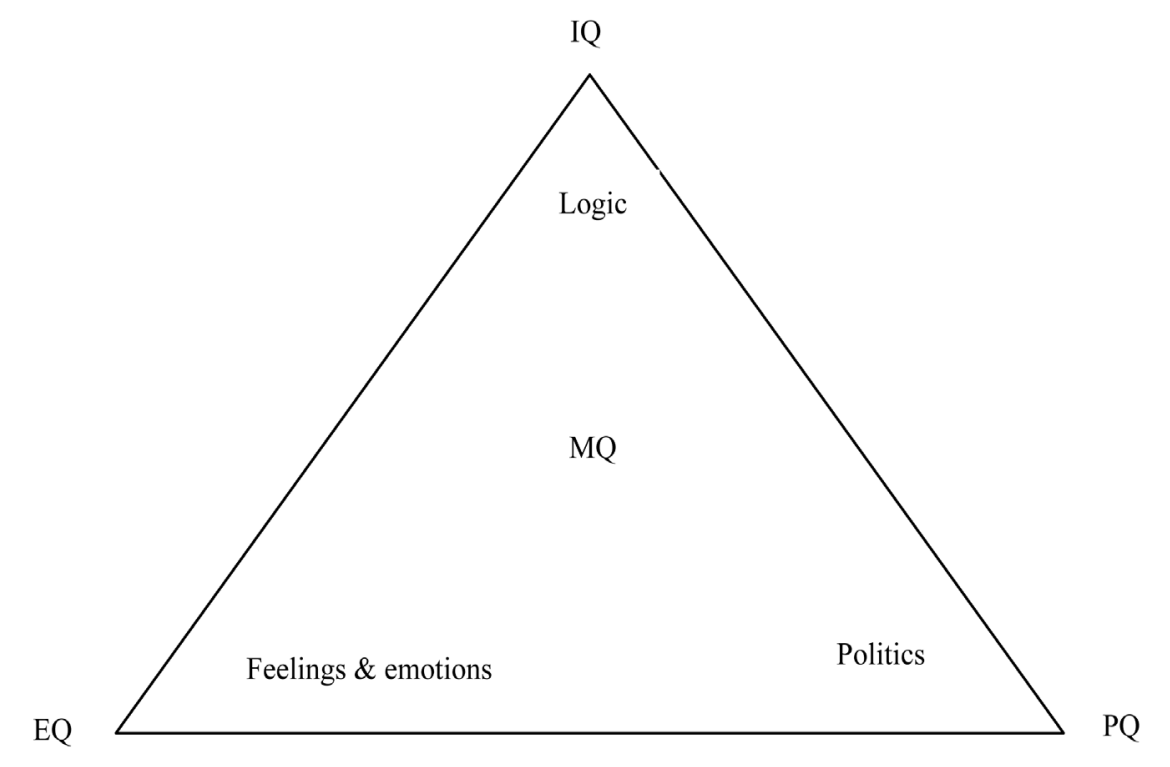

Figure 1. Managerial quotient pyramid in Owen’s viewpoint. 


\section{Methods}

This study aimed to systematically review the managerial quotient among the managers of Tehran University of Medical Sciences. Accordingly, the Persian-language articles, dissertations and books in the Iranian Scientific Journals, websites, and data bases, as well as the English-language articles and books in the journals of inside and outside of Iran were searched. The researchers used the Preferred Reporting Items for Systematic Reviews and Meta-Analyses (PRISMA), which is a standard guideline for systematic reviews and contains 27 items [39] (Goodarzi et al., 2012).

\subsection{Research Question}

In the current study, in order to find studies published electronically until January 2016, the articles published in the local and international Journals, book, and dissertation available in the databases were used as follows:

1: The keywords of “Intelligence Quotient”, “Emotional Quotient”, “Spiritual Quotient”, “Moral Intelligence”, "Cultural Intelligence”, "Political Intelligence”, and “ Managerial Quotient”, “Tehran University of Medical Science”, "Iran”, and their combinations, as well as their Persian equivalence were used to search for Persian and English language articles, books, and websites in the Iranian and international databases.

2: The search was limited to all Persian-language articles published in the Iranian scientific journals, books, and dissertations in local databases, and the related English-language articles published in Iranian and non-Iranian journals, books, and website, indexed in the selected databases from 1985 to November 2015. This research was carried out from March 2015 to November 2015.

\subsection{Data Bases Used to Systematically Search}

For finding the related articles, books and websites, the researchers searched the Iranian electronic databases, including SID, Iran Medex, Iran Doc, Magiran, as well as all non-Iranian electronic databases, including Medline, Embase, Scopus, Emerald, PubMed, Google and Google Scholar.

\subsection{Article Selection Criteria}

Five inclusion criteria were applied: 1) The report included managerial quotient; 2) the data required for analysis were available (by access to the abstract and full text of the publication or by request from author); 3 ) the study's observations were limited to managerial quotient and the kinds of intelligences within the boundaries of Iran; 4) the report was published in Persian or English. The abstract and the full text of all related articles, documents and reports were obtained.

First, the article and book titles were studied, and the duplicates were removed. Then, the remaining references were carefully studied by the researchers. All available Persian and English-language articles published in Iranian and non-Iranian scientific journals whose abstract and full texts were chosen and unrelated articles were removed.

\subsection{The Exclusion Criteria}

The exclusion criteria were : the lack of access to the full texts, letters to editors, article with the same title and topic which were published in the Persian and English languages, articles whose study population and samples had not been determined or the validity and reliability of their data collection tools had not been explained.

\subsection{Data Extraction, Variables and Data Analysis}

For reviewing the selected references, a data extraction form, developed by the researchers according to the aim of study, was used. This form included sections for writing the characteristics of each selected articles, books, and thesis including the authors' name, the year of publication, the aim of studies, the types of studies, materials \& methods, and the results of the reference.

At this stage, two researchers involved in the selection of contents and data extraction. The main characteristics of selected studies and their results have been summarized according to the following variables:

-Types of studies: According to the types of study design, the classification of studies was as follows: descriptive cross-sectional studies, descriptive analytical studies, qualitative studies, review articles, and systematic reviews. 
-The language to study: This variable showed that they had been published in Persian or English language.

-The year of publication: This variable was included 1985 to 2016.

\subsection{A Review of the References Published}

In this systematic review, the managerial quotient evaluation used in Tehran University of Medical Sciences was reviewed. The search in databases was carried out from Sep 2015 to Jan 2016 based on the keywords and search strategies, and 98 articles, books and dissertations from 733 ones were selected. The titles and abstracts of all articles were studied systematically according to their relationship with the studied topic and the inclusion and exclusion criteria. At this stage 33 articles were excluded from the study, because there was not any access to their full texts, and also because they had been published by two languages (English as well as Persian). Overall 69 articles, 6 books, and 6 dissertations remained. After excluding articles which did not meet the inclusion criteria, the articles which had more complete data and were more relevant to the aim of study were selected and their full texts were given to two independent judges and experts in the human resource management. The difference between them was explained in three - member committee, in the presence of project manager and supervisor and the related decisions were made. Eventually, 83 references were selected.

Consequently, the references had been published from 2010-2015, and 28\% of them published from 2006-2010. The rest of them (42\%) had been published from 1985-2009.

\section{Findings}

According to a study by Shoghi in hospitals of Tehran University of Medical Sciences, more than 50 percent of the managers in those hospitals enjoyed really high, very high, relatively high levels of managerial art. In this study, the purpose of researcher was to show and assess the IQ, and the other technical, conceptual, moral, and political skills of the studied hospitals managers [40] (Shoghi, 2011).

Yusefzade prepared a questionnaire based on Zohar's model about Spiritual Quotient. This questionnaire was distributed among hospitals managers of Tehran University of Medical Sciences after confirming its validity and reliability. This questionnaire contained 42 items and 4 components including "Being vision and value led", “The Positive Use of Adversity”, "Humanity” and finally "Self Awareness and Compassion”. The results of this research showed that hospital managers of Tehran University of Medical Sciences attained the average of 4.43 in "Being vision and value led", 3.18 in "The Positive Use of Adversity", 4.23 in "Humanity" and 3.86 in "Self Awareness and Compassion”. With regard to their average spiritual quotient of upper than 3, it seems that these hospital managers, who are at the confidence level of 95\%, enjoy a high rate of spiritual quotient. Moreover, based on Pearson correlation test, there was a significant relationship between managers' spiritual quotient and their transformative style of leadership; that is to say, the studied managers have high transformative leadership power based on their high spiritual quotient [41] (Yusefzadeh, 2012).

Bigdeli assessed cultural intelligence among the headquarters managers of Tehran University of Medical Sciences using the standard cultural intelligence questionnaire related to US Cultural Intelligence Center. This questionnaire had 19 items and 4 sections. The results showed that these managers were categorized as "very desirable”, “desirable” and "relatively desirable” based on megacognitive, cognitive, motivation, cultural behavior, and generally cultural intelligence factors. Overall, their cultural intelligence average was upper than the average limits. Furthermore, megacognitive and motivation factors among studied managers were assessed higher in comparison with cognitive and behavioral ones. Using Pearson test, it was concluded that there was a significant relationship between cultural intelligence and its components with managers' performance $(\mathrm{P}=0.02)$. Using One Way ANNOVA, it was concluded that there was not a significant relationship between cultural intelligence and years of work experience, work location of managers, and ethnicity, although this relationship was reported negative regarding managerial level. In other words, cultural intelligence among top managers was higher in comparison with middle and junior managers $(P=0.009)$ [42] (Bigdeli, 2012).

Javadi Ghaleh (2013) reported in his research entitled "assessing spiritual and moral intelligence among the managers of faculties of Tehran University of Medical Sciences” that the rate of spiritual and moral quotient among the mentioned managers was higher than the average. Moreover, it was announced that the average spiritual intelligence among respective managers was higher in all educational levels. Although, the negative relationship between the rate of spiritual and moral intelligence among the managers of faculties with different levels of educational degrees was significant. In other words, managers with lower educational degrees enjoyed 
higher spiritual and moral quotient. The other results of this research showed that there was a negative relationship between moral intelligence and their creativity $(\mathrm{P}=0.02)$. That is to say, when moral intelligence increases, creativity decreases. Besides, there was a negative relationship between creativity and "being vision and value lad” as well as "humanity” as spiritual intelligence elements. Therefore, it seems, with strengthening and increasing of these two elements of spiritual intelligence, the creativity is decreased. Also, there was a significant relationship between "self-awareness and compassion" and "the positive use of adversity" with the managers' creativity. Using correlation analysis test, it was stated that there was a significant relationship between moral intelligence and spiritual intelligence. Moreover, using stepwise regression, it was indicated that moral intelligence can specify $8 \%$ of creativity variance, while spiritual intelligence can specify $4 \%$ of creativity variance. Therefore, $8 \%$ of changes in creativity variance were due to moral intelligence, while $4 \%$ of changes were because of spiritual intelligence. Applying multiple regression between moral and spiritual intelligence with creativity, it was indicated that moral and spiritual intelligence cannot predict creativity, and the effect of these two types of intelligence on creativity was not to that extent which can enhance creativity significantly among the managers [43] (Javadi Ghaleh, 2013).

Arab et al. stated that EQ is the major factor in leaders' effectiveness, and managers' success in organizations. These researches were induced a descriptive analytical, and cross-sectional study among 120 top and middle managers, and 480 employees of public and private hospitals in Tehran also including Tehran University of Medical sciences hospitals. They declared that the amount of EQ among hospital managers were above 50\% and was desirable. Furthermore, there was a significant relationship between EQ and managers’ performance. Besides, "social skills” was rated as the highest, and "self motivation” as the lowest as EQ elements among this managers [44] (Aarab et al., 2012).

Ghasemi who studied “the investigation of EQ influence on middle and junior managers' performance of the headquarters of Tehran University of Medical Sciences”, showed that those managers had high amount of EQ, and there was a significant relationship between EQ and their managerial performance. That is to say, whatever, the managers' EQ is increased, their performance also increased [45] (Ghasemi, 2013) (Table 1).

\section{Discussion}

In recent years, intelligence has not just been considered as Intelligence Quotient (IQ), but it includes other scopes. Goldman and Hedlund \& Sternberg believe that IQ can only assure 20 to 30\% of managers’ job success, while the other aspects of intelligence are also very impressed managers' success (Goleman, 1996; Hedlund \& Sternberg, 2000). Salovey states that managerial intelligence depends on emotional factor [46] (Salovery, 2002). Mayer \& Salovery also emphasize that EQ is the ability to recognize the other people's feelings and sentiment, and appropriate respond to them [47] (Mayer \& Salovery, 1997). Although, Mojtaba et al. reported that there was a positive significant correlation between teaching hospitals’ managers' IQ with employees' organizational commitment in Shiraz, Iran [48] (Mojtaba et al., 2013).

On the other hand, spiritual intelligence is the innate intelligence of a human. This intelligence facilitates attaining the spiritualism of life which includes purposefulness, nobility, and function of human's life. It seems that spiritual intelligence plays a crucial role in enrichment of EQ and vice versa. In fact, these two kinds of intelligences influence each other directly. Within the past ten years, researchers have been interested to study EQ and its role in effective and transformative leadership. Their findings show that EQ plays a significant role in effectiveness of transformative leadership [49] (Dulewicz \& [50] Higgs 2005; Higgs, 2003). Even though, some of the researchers believe that EQ can predict more than $80 \%$ of managers' effectiveness. Therefore, there is a significant relationship between EQ and transformative style of leadership [51] (Nasiripour et al., 2009; [52] Molazemian et al., 2013). Nonetheless, it is believed the leaders use EQ to satiate their followers' emotionality, not logically [53] (Humphreys \& Einstein 2008). However, "Brown et al." could not find a significant relationship between EQ and transformative leadership. Although, they believed that this finding cannot deny the existence of such a relationship, because they had chosen a different scale for measuring EQ [54] (Brown et al., 2006). This significant relationship could find between EQ and transformative leadership, but not beyond IQ [55] (Antomakis, 2007; [56] Sivanathan \& Felken, 2002).

Muller \& Tuner showed that using EQ elements such as critical thinking, influence, motivation and consciousness can help the managers to success for attaining organizational goals [57] (Muller \& Tuner, 2010). 
Table 1. The types of studies used managerial quotient in Tehran University of Medical Sciences.

\begin{tabular}{|c|c|c|c|}
\hline First author & The type of quotient & Objectives & The results of managerial quotient \\
\hline $\begin{array}{l}\text { Shoghi } \\
\text { (2011) }\end{array}$ & $\begin{array}{l}\text { Intelligence quotient } \\
\text { measurement based on } \\
\text { researcher's } \\
\text { constructed } \\
\text { questionnaire }\end{array}$ & $\begin{array}{l}\text { Determination of managerial art } \\
\text { and intelligence quotient } \\
\text { rate among Tehran University } \\
\text { of Medical Sciences hospitals }\end{array}$ & $\begin{array}{l}\text { More than } 50 \% \text { of the managers in } \\
\text { hospitals of Tehran University of } \\
\text { Medical Sciences enjoyed really high, } \\
\text { very high, and relatively high levels of } \\
\text { managerial art and intelligence quotient }\end{array}$ \\
\hline $\begin{array}{l}\text { Yusefzadeh } \\
\text { (2012) }\end{array}$ & $\begin{array}{l}\text { Spiritual quotient } \\
\text { measurement based } \\
\text { on Zohar's model }\end{array}$ & $\begin{array}{l}\text { Determination of spiritual quotient and } \\
\text { its four components rate among } \\
\text { hospitals managers of Tehran } \\
\text { University of Medical Sciences } \\
\text { and analyzed the relationship } \\
\text { between spiritual quotient with } \\
\text { their transformative style of leadership }\end{array}$ & $\begin{array}{l}\text { It seems, these hospitals managers enjoy } \\
\text { a high rate of spiritual quotient. There was } \\
\text { a significant relationship between managers' } \\
\text { spiritual quotient and their transformative } \\
\text { style of leadership, and the managers had } \\
\text { high transformative leadership power } \\
\text { based on their high spiritual quotient }\end{array}$ \\
\hline $\begin{array}{l}\text { Bigdeli } \\
\text { (2013) }\end{array}$ & $\begin{array}{l}\text { Cultural intelligence } \\
\text { measurement based on } \\
\text { standard questionnaire } \\
\text { related to us cultural } \\
\text { intelligence center }\end{array}$ & $\begin{array}{l}\text { Determination of cultural intelligence } \\
\text { and its components rate among } \\
\text { headquarters managers of Tehran } \\
\text { University of Medical Sciences, } \\
\text { and analyzed the relationship } \\
\text { between cultural intelligence } \\
\text { with managers' performance } \\
\text { and their demographic details }\end{array}$ & $\begin{array}{l}\text { The results showed that these managers' } \\
\text { cultural intelligence average was upper than } \\
\text { the average limits. There was a significant } \\
\text { relationship between cultural intelligence } \\
\text { and its components with managers' } \\
\text { performance and years of work experience, } \\
\text { work location, and ethnicity }\end{array}$ \\
\hline $\begin{array}{c}\text { Javadi Ghaleh } \\
\text { (2013) }\end{array}$ & $\begin{array}{c}\text { Spiritual and moral } \\
\text { intelligence based on } \\
\text { standard questionnaires }\end{array}$ & $\begin{array}{l}\text { Determination of moral and spiritual } \\
\text { intelligence rate and its elements } \\
\text { among the managers of Tehran } \\
\text { University of Medical Sciences } \\
\text { faculties, and analyzed the } \\
\text { relationship between these } \\
\text { intelligences with their } \\
\text { demographic details and creativity }\end{array}$ & $\begin{array}{l}\text { The rate of spiritual and moral intelligence } \\
\text { was higher than the average. Also, the } \\
\text { managers with lower educational degrees } \\
\text { enjoyed higher spiritual and moral intelligence } \\
\text { There was significant relationship between } \\
\text { the managers' moral intelligence and their } \\
\text { creativity. It was indicated that moral } \\
\text { intelligence can specify } 8 \% \text { of creativity } \\
\text { variance, while spiritual intelligence can } \\
\text { specify } 4 \% \text { of creativity variance. }\end{array}$ \\
\hline $\begin{array}{l}\text { Arab et al. } \\
\text { (2011) }\end{array}$ & $\begin{array}{l}\text { Emotional quotient } \\
\text { based on standard } \\
\text { questionnaire }\end{array}$ & $\begin{array}{l}\text { Determination of emotional } \\
\text { quotient rate between top and } \\
\text { middle managers, and employees } \\
\text { of Tehran University of } \\
\text { Medical Sciences hospitals }\end{array}$ & $\begin{array}{l}\text { The amount of emotional quotient among } \\
\text { the managers of employees of Tehran } \\
\text { University of Medical Sciences hospitals } \\
\text { was desirable. Also, there was a significant } \\
\text { relationship between managers' emotional } \\
\text { quotient and their performance. }\end{array}$ \\
\hline $\begin{array}{l}\text { Ghasemi } \\
\text { (2013) }\end{array}$ & $\begin{array}{l}\text { Emotional quotient } \\
\text { based on standard } \\
\text { questionnaire }\end{array}$ & $\begin{array}{l}\text { Determination of emotional quotient } \\
\text { among middle and junior managers, } \\
\text { and analyzed the relationship } \\
\text { between the EQ and their } \\
\text { managerial performance. }\end{array}$ & $\begin{array}{c}\text { These managers had high amount of EQ, } \\
\text { and there was a significant relationship } \\
\text { between EQ and their } \\
\text { managerial performance. }\end{array}$ \\
\hline
\end{tabular}

Slaski \& Cartwright reported that there was a significant relationship between managers’ EQ with distress, eustress, general health, moral considerations, quality of work life, and managerial performance. Namely, managers who had higher rates of EQ, enjoyed less distress, higher general health, and better managerial performance [58] (Slaski \& Cartwright, 2002). Barling et al. proved that three elements of transformational leadership, that is idealized influence, including idealized attributes, idealized behaviors, and inspirational motivation, conceptual encouragement, and individual consideration are different from each other based EQ level [59] (Barling et al., 2000). The researches' finding induced in Iran showed that most of the managers of Tehran University of Medical sciences had high rate of EQ.

Also, the previous studies reported that hospital managers and directors of Tehran University of Medical Sciences schools enjoyed a high spiritual and moral quotient. Managers who enjoy high level of spiritual quotient, have high productivity, and efficient leadership style [60] (Bagherpour \& Abdollahzadeh, 2012; Amaram, 2009).

Although, significant relationship between self efficiency, i.e. thought, belief and emotion style with spiritual quotient was proved by some researchers [61] (Golchin \& Sanjary, 2012). Spiritual quotient and self efficiency are supposed to play a significant role to help the managers to develop their efficiency and performance and or- 
ganizational commitment (Golchin \& Sanjari, 2013; [62] Ghorbani et al., 2013).

Mahmoudi et al. reported moral intelligence was consisted of honesty, responsibility, compassion and forgiveness have a significant relationship with team leadership [63] (Mahmoudi, et al., 2013; [64] Siadat et al., 2009). Also, it seems that there is a significant relationship between moral intelligence with managers' self confidence, and they could improve profitability and self-confidence in all organizations [65] (Esmaili Tarzi et al., 2012). Nevertheless, moral leadership has been discussed theoretically today, but few studies have induced about moral dimensions. Turner et al. showed that managers with higher moral intelligence are more capable of showing transformative and interactive leadership behaviors. However, there were not any significant relationships between managers' moral intelligence and interactive leadership behaviors [66] (Tuner et al., 2002). Although, Tehran University of Medical Sciences managers had high rate of moral intelligence, but there was no significant correlation between moral intelligence and creativity as a dimension transformative leadership.

Watson et al. reported that managers with high rate of cultural intelligence, enjoy three factors such as cultural knowledge, cultural considerations, and cultural skills that was significant correlation between managers' cultural intelligence with their success [67] (Watson et al, 1993; [68] Thomes \& Kerr, 2009). Thomas et al. found that cultural diversity, cultural-social norms of a team work, and the relative cultural gap between the team members, influence team effectiveness, and homogenous team members have better performance culturally in comparison with culturally heterogeneous groups [69] (Thomas et al., 2006). Grishem \& Derek showed that five elements of cultural intelligence can enable the managers to work successfully and effectively in different culture [70] (Grishem \& Derek, 2008). Van Driel announced that enjoying a high rate of cultural intelligence among managers and leaders has a significant relationship with organizational high performance and effectiveness (Van Driel, 2008; [71] Rahimnia et al., 2010). Ang et al. indicated that there was a significant relationship between managers' cultural intelligence and Chen \& Isa determined that there was a relationship among cultural intelligence elements. That is to say that cultural shock is less among the managers who enjoy higher rates of cultural intelligence (Ang et al., 2007; Chen \& Isa, 2003).

Parhizgari declared that mega-cognitive items and motivation of cultural intelligence had a significant relationship with managers' effectiveness of universities [72] (Parhizgari, 2000). Moreover, "Abzari et al., also reported that there was a significant relationship between team effectiveness and cultural intelligence of team members. In other words, whatever the effectiveness of teams with cultural diversity is higher, their compatibility of team members with different cultural norms will be higher. Cultural intelligence along with EQ is fundamental of the managers' organizational success at worldwide level [73] (Abzari et al., 2011; [74] Moshabaki \& Tizro, 2009; [75] Taslimi et al., 2009). It is concluded that managers' high cultural intelligence created a competitive and strategic climate in the world market. In fact, cultural intelligence is the necessary tool for the managers and leaders' in the world arena [76] (Fayazi \& Jan Nesar Ahmadi, 2006; [77] Moshabaki \& Ramous, 2006).

Political intelligence includes a series of skills and behaviors, needed for the managers in order to manage their political climate or political behaviors effectively. Political intelligence helps the managers to understand the source of power in their organizations appropriately, and recognize the extra and alternative resources to attain the power [78] (Woocher, 2016). Nowadays, political intelligence development is considered as an important factor in management training. High political intelligence among managers makes them treat wisely in organizations, assessing their organizations positions systematically, and pass different stages to understand the political state of their organizations [79] (Baddeley, 1987). Political intelligence prevents the conflict among the managers. Several instructions have been introduced to increase the managers' political intelligence. Thus, managers' communicative skills should be strengthened first, and their face to face meeting with the employees and organizational networking should be developed in order to promote common issues in all departments, and finally strength how the managers' influence their employees for appropriate outcomes [80] (Adams \& Zanzi, 2006). High political intelligence should promote competencies of managers for controlling and directing influence and power tools (Bourgeois \& Singh, 1985).

Finally, Asadi et al. indicated that there was positive correlation between organizational quotient derived from "Albrecht” with hospitals performance indices, including bed occupation rate, surgery number to operating room ratio, bed turn over interval, and length of stay [81] (Asadi et al., 2014).

\section{Conclusions}

This systematic review study could assess the managerial intelligence among the managers of Tehran University 
of Medical Sciences for the first time in the field of Iranian health care. Although managerial intelligence is a hybrid quotient which includes IQ, EQ and political intelligence, but it seems that moral intelligence, spiritual quotient and cultural intelligence are also shared in managerial quotient according to studies induced in Tehran University of Medical Sciences. Furthermore, the research findings of other studies with regard to managerial quotient, and the need for widespread use of managerial quotient as a hybrid and comprehensive quotient in managing organizations, especially health care organizations, are in accordance with findings of the current research which emphasized on utilizing managerial quotient among the managers in this field.

Therefore, based on the findings, discussion and analysis of the results of current study, it can be suggested that managerial quotient is an important and necessary factor before selection and appointment of managers. However, there are other factors necessary for selection of efficient managers which were not mentioned in current study. It is also suggested that managerial quotient courses should be included in educational curriculum of health-care management BSc., MSc., and even in PhD level which leads to educate the experts and scientists in this field. Moreover, we suggest the hospitals managers in Iran should be trained for managerial quotient by establishment of training courses and workshops, and managerial quotient should utilize as a factor for managers selection in Iranian health care organizations just like hospitals.

\section{Limitation \& Implication}

The limitations of any study are magnified when the realities of taking the concepts and techniques developed in one culture are applied to another culture. Also, one of the main limitations of the present study is that, it was conducted at one specific time. Therefore, this information-collection process is convenient for present research.

\section{Ethical Consideration}

Ethical issues, including informed consent, misconduct, data fabrication and/or falsification, double publication, redundancy, etc. have been completely observed by the authors.

\section{Acknowledgement}

The current study was supported by Research and Technology Vice-Chancellor of Tehran University of Medical Sciences. The researchers are extremely grateful to them.

\section{References}

[1] Amram, J. (2009) Intelligence beyond IQ: The Contribution of Emotional and Spintual Intelligences to Effective Business Leadership. A Dissertation in Partial Fulfillment of the Requirements for the Degrees of Doctor of Philosophy in Clinical Psychology. Institute of Transpersonal Psychology, Palo Alto.

[2] Avolio, B.J., Zhu, W., Koh, W. and Bhatia, P. (2004) Transfermational Leadership \& Organizational Commitment: Mediating Role of Psychological Empowerment \& Moderating Role of Structural Distance. Journal of Organizational Behavior, 25, 951-968. http://dx.doi.org/10.1002/job.283

[3] Appelbaum, S., Bartolomucci, N., Beaumier, E., Boulanger, J., Carrigan, R., et al. (2004) Organizational Citizenship Behavior: A Case Study of Culture, Leadership and Trust. Management Decision, 42, 13-40. http://dx.doi.org/10.1108/00251740410504412

[4] Loehlin, J.C., Perloff, Q., Sternberg, R.J. and Urbina, S. (1996) Intelligence: Knows and Unknowns. American Psychologist, 5, 77-101.

[5] Anonymous (2015) Intelligence. American Psychological Association. http://www-apa.org/topics/intelligence.httm

[6] Gardner, H. and Hatch, H. (1989) Multiple Intelligences to School: Educational Implications of the Theory of Multiple Intelligence. Educational Researcher, 18, 4-9. http://dx.doi.org/10.2307/1176460

[7] Gardner, L. and Stough, C. (2002) Examining the Relationship between Leadership and Emotional Intelligence in Senior Level Manager. Leadership \& Development Journal, 23, 68-79. http://dx.doi.org/10.1108/01437730210419198

[8] Gardner, H. (2006) Changing Minds: Heart and Science of Changing Our Own and Other People's Mind (Leadership for Compound God). Harward Business Review Press, Boston, 72-85.

[9] Sternberg, R.J., Grigorenko, E.L. and Bundy, D.A. (2001) The Practice Value of IQ. Merrill-Palmer Quarterly, 47, 1-41. http://dx.doi.org/10.1353/mpq.2001.0005

[10] Bjorkqvist, K. and Oysterman, K. (2000) Social Intelligence-Empathy-Aggression? Aggression and Violent Behavior, 


\section{5, 191-200. http://dx.doi.org/10.1016/S1359-1789(98)00029-9}

[11] Crowne, K.A. (2009) The Relationship among Social Intelligence, Emotional Intelligence and Cultural Intelligence. Organization Management Journal, 6, 178-163. http://dx.doi.org/10.1057/omj.2009.20

[12] Goleman, D.D. (1996) Emotional Intelligence. Why It Can Matter More than IQ. Learning, 24, 49-50.

[13] Hedlund, J. and Sternberg, R. (2000) Too Much Intelligence? Integrating Social, Emotional, and Practical Intelligence. In: Bar-On, R. and Parker, J., Eds., The Handbook of Emotional Intelligence: Theory, Development, Assessment and Applications of Home, School, and in the Workplace, Jossey-Bass, San Francisco, 136-167.

[14] Criechton, J.C. (2008) A Qualitative Study of Spiritual Intelligence in Organizational Leaders. Ancient International University, San Francisco Bay, 92-105.

[15] Zohar, D. (2005) Spiritual Intelligence Leadership. Leader to Leader, 38, 1-8.

[16] Bennis, W.G. and Nanus, B. (1985) Leaders: The Strategically for Taking Change. Harper \& Row, New York, 23-30.

[17] Bienstokh, C., Demoranville, W.C. and Smith, K.R. (2003) Organizational Citizenship Behavior and Service Quality. Journal of Services Working, 17, 357-378. http://dx.doi.org/10.1108/08876040310482775

[18] Boehnke, K., Bontis, N., Distefano, J.J. and Distefano, A.C. (2003) Transformational Leadership: An Examination of Cross-National Differences and Similarities. Leadership \& Organizational Journal, 24, 5-15. http://dx.doi.org/10.1108/01437730310457285

[19] Wiggles Worth, C. (2004) Spiritual Intelligence and Why It Matter. The Inner Words Messenger, a Newsletter to Spark the Inner Journal. www.consciouspursuits.com

[20] Emmons, R.A. (2000) Is Spirituality an Intelligence? Motivation, Cognition, and Psychology of Ultimate Concern. International Journal for the Psychology of Religion, 10, 3-26. http://dx.doi.org/10.1207/S15327582IJPR1001_2

[21] Nobel, K.D. (2008) Riding the Wind Horse: Spiritual Intelligence and the Growth of the Self. Hampton Press, Cresskill, 112-116.

[22] Sisk, D.A. and Torrence, E.P. (2009) Spiritual Intelligence: Developing Higher Consciousness. Creative Education Foundation Press, Buffalo, 15-25.

[23] Borba, M. (2005) Building Moral Intelligence: The Seven Essential Virtues That Teach Kids to Do the Right Thing. The University of Michigan, Jossey Bass, San Francisco, 55-70.

[24] Lennick, D. and Kiel, F. (2005) Moral Intelligence. Wharton University of Pennsylvania, Philadelphia, 16.

[25] Flite, C.A. and Harman, L.B. (2013) Code of Ethics: Principles for Ethical Leadership. Perspectives in Health Information Management, 10, $1 \mathrm{~d}$.

[26] Mohammadi, S., Nakhaei, F. and Roshanzadeh, M. (2013) Moral Intelligence in Nursing: A Cross-Sectional Study in East of Iran. Iranian Journal of Medical Ethics, 6, 57-66. (In Persian)

[27] Early, P.C. and Ang, S. (2003) Cultural Intelligence: Individual Interactions across Culture. Stanford Business Books, Stanford, 12-18.

[28] Ang, S., Van Dyne, L., Koh, C., Ngk, Y., Templer, K.J., et al. (2007) Cultural Intelligence: Its Measurement and Effects on Cultural Judgment and Decision Making, Cultural Adaptation and Task Performance. Management \& Organization, 3, 335-371. http://dx.doi.org/10.1111/j.1740-8784.2007.00082.x

[29] Van Driel, M. (2008) Cultural Intelligence as an Emergent Organizational Level Contract. Florida Institute of Technology, Melbourne, FL, 307.

[30] Mahjoub, M.E. (2004) Cultural Quotient: Dominant Functional Performance. Journal of Management Selection, 43, 94-96. (In Persian)

[31] Chen, L. and Isa, M. (2003) Intercultural Communication and Cultural Learning: The Experience of Japanese Visiting Students in the U.S. Howard Journal of Communications, 14, 75-96. http://dx.doi.org/10.1080/10646170304269

[32] Agha Seyed Hosseini, S.R. (2015) The Relationship between Managerial Quotient with Employment of Managers in Internal Companies. (In Persian) www.Iranmct.com

[33] Jensen, K. (2012) Intelligence Is Overrated: What You Really Need to Succeed. www.forbes.com

[34] Owen, J. (2006) How to Manage. Art of Making Things Happen. 3rd Edition, Prentice Hall, London, 45-60.

[35] Sadeghi, A. (2015) 4 Employees in Every Company That Must Have High Emotional Intelligence. Titanium Success. www.titaniumsuccess.com

[36] Hosseini, S.S. The Role of Emotional Quotient in Organizational Management. Retrieved 2015. (In Persian) www.smsplz.com

[37] Bourgeois, L.J. and Singh, J.V. (1985) Organizational Slack and Political Behavior among Top Management Teams. Academy of Management Proceedings, (Meeting Abstract Supplement), 43-47. 
[38] Treadway, D., Hochwarter, W.A., Kacmar, C.J. and Ferris, G.R. (2005) Political Will, Political Skill, and Political Behavior. Journal of Organizational Behavior, 26, 229-245. http://dx.doi.org/10.1002/job.310

[39] Goodarzi, G., Nasab, M.H.I., Mehr, N.J., Rostami, K., Omidfar, R. and Mahooti, F. (2012) Hospital Performance Assessment of Lorestan University of Medical Sciences. Payesh, 11, 309-315. (In Persian)

[40] Shoghi, S.H. (2011) Assessment of Management Art among Tehran University of Medical Sciences. MSc. Dissertation in Health Care Management, Tehran University of Medical Sciences, Tehran. (In Persian)

[41] Yousefzadeh, N. (2012) The Survey of Relationship between Spiritual Quotient with Transformational Leadership Style among Senior Managers of Tehran University of Medical Sciences. MSc. Dissertation in Health Care Management, Tehran University of Medical Sciences, Tehran. (In Persian)

[42] Bigdeli, Z. (2014) Assessing the Relationship between Cultural Quotient with Job Performance among the Headquarters Managers of Tehran University of Medical Sciences. MSc. Dissertation in Health Care Management, Tehran University of Medical Sciences, Tehran. (In Persian)

[43] Javadi Ghaleh, E. (2014) Study of Relationship between Spiritual Quotient, Moral Intelligence with Creativity among the Managers of Tehran University of Medical Sciences Schools. MSc. Dissertation in Health Care Management, Tehran University of Medical Sciences, Tehran. (In Persian)

[44] Arab, M., Zeraati, H., Shabaninejed, H., Lavasani, M., Akbari Sari, A. and Varmaghani, M. (2011) Study of Managers Emotional Intelligence and Its Relation with Their Performance in Selected Public and Private Hospitals in Tehran. Hospital Journal, 2, 1-7. (In Persian)

[45] Ghasemi, S. (2012) The Survey of Emotional Intelligence Effect on Central Headquarters Managers of Tehran University of Medical Sciences. MSc. Dissertation in Management, Islamic Azad University, Tehran Central Branch, Tehran. (In Persian)

[46] Salovery, P. (2002) Emotions: Current Issues and Failure Directions. Guilford Press, New York, 72-80.

[47] Mayer, J.D. and Salovey, P. (1997) What Is Emotional Intelligence? In: Salovey, P. and Sluyer, D.J., Eds., Emotional Development and Emotional Intelligence: Educational Implications, Basic Books, New York, 55-90.

[48] Mojtaba, F., Keshtkaran, V., Hedayati, S.P., Hatam, N. and Fathi, V. (2013) The Relationship between Intelligence Quotient with Organizational Commitment among Teaching Hospitals Administrators of Shiraz, Iran. Journal of Public Health of Yazd University of Medical Sciences, 12, 1-10. (In Persian)

[49] Dulewicz, V. and Higgs, M. (2005) Assessing Leadership Styles and Organizational Context. Journal of Management Psychology, 200, 105-123. http://dx.doi.org/10.1108/02683940510579759

[50] Higgs, M. (2003) How Can We Make Sense of Leadership in the 21th Century? Leadership and Organization Development, 24, 271-284.

[51] Nasiripour, A.A., Raisi, P. and Jafari, M. (2009) The Relationship between Emotional Intelligence with Leadership Style among Tehran Social Security Hospitals Administrators. Quarterly Journal of Education, 7, 18-26. (In Persian)

[52] Molazemian, M.H., Seidi, M. and Karimi, H. (2013) Relationship between Nurse Managers Emotional Intelligence and Their Transformational Leadership Styles. Quarterly Journal of Nursing Management, 1, 63-69. (In Persian)

[53] Humphreys, J.H. and Einstein, W.O. (2008) Noting New “under the Sun”: Transformational Leadership from a Historical Perspective. Management Decision, 41, 85-95. http://dx.doi.org/10.1108/00251740310452934

[54] Brown, F.W., Bryant, S.E. and Reilly, M.D. (2006) Does Emotional Intelligence-As Measured by the EQI-Influence Transformational Leadership and/or Desirable Outcomes? Leadership \& Organization Development Journal, 27, 330-351. http://dx.doi.org/10.1108/01437730610677954

[55] Antomakis, J. (2007) On Why "Emotional Intelligence” Will Not Predict Leadership Effectiveness beyond IQ or the "Big Five”: An Extension and Rejoinder. Organizational Analysis, 12, 171-182. http://dx.doi.org/10.1108/eb028991

[56] Sivanathan, N. and Felken, G.C. (2002) Emotional Intelligence, Moral Reasoning and Transformational Leadership. Leadership \& Organization Development Journal, 23, 198-204. http://dx.doi.org/10.1108/01437730210429061

[57] Muller, R. and Turner, R. (2010) Leadership Competency Profiles of Successful Project Managers. International Journal of Project Management, 28, 437-448. http://dx.doi.org/10.1016/j.ijproman.2009.09.003

[58] Slaski, M. and Cartwright, S. (2002) Health, Performance and Emotional Intelligence: An Explanatory Study of Retail Managers. Stress and Health, 18, 63-68. http://dx.doi.org/10.1002/smi.926

[59] Barling, J., Slater, F. and Kelloway, E.K. (2000) Transformational Leadership and Emotional Intelligence: An Explanatory Study. Leadership \& Organization Development Journal, 21, 157-161. http://dx.doi.org/10.1108/01437730010325040

[60] Bagherpour, M. and Abdollahzadeh, H. (2012) Relationship between Spiritual Intelligence and Leadership Style of Managers of Secondary Schools in Gorgan, Iran. Quarterly Journal of New Approaches in Educational Administration, No. 2, 87-97. (In Persian) 
[61] Gochin, M. and Sanjari, A.R. (2013) The Study of Relationship between Spiritual Quotient with Staffs Self-Efficiency: A Case Study. International Academy of Organizational Behavior Management, 3, 22-30. (In Persian)

[62] Ghorbani, M., Haghighi, M., Mohammadali Tajrishi, M.A. and Rasteh Moghadam, A. (2013) The Public Sector Relationship between Spiritual Intelligence and Organizational Commitment. Quarterly Journal of Management and Development Process, 25, 68-92. (In Persian)

[63] Mahmoudi, M.T., Siadat, S.A. and Shadanfar, F. (2013) The Relationship between Moral Quotient with Team Leadership among Head of Educational Departments in Universities of Zahedan, Iran. Journal of Education and Assessment (Education Science), 5, 107-126. (In Persian)

[64] Siadat, S.A., Kazemi, I. and Mokhtaripour, M. (2001) The Relationship between Moral Intelligence with Team Leadership in Administrators from Faculty Members Point of View at Isfahan University of Medical Sciences, Isfahan, Iran. Journal of Health Administration, 12, 61-69. (In Persian)

[65] Esmaili Tarzi, Z., Beheshtifar, M. and Esmaili Tarzi, H. (2012) The Relationship between Moral Quotient with Managers Self Confidence. Iranian Association for Ethics in Science and Technology, 8, 70-84. (In Persian)

[66] Turner, N., Barling, J., Epitropaki, O., Butcher, V. and Milner, C. (2002) Transformational Leadership and Moral Reasoning. Journal of Applied Psychology, 87, 304-311. http://dx.doi.org/10.1037/0021-9010.87.2.304

[67] Watson, W.E., Kuman, K. and Michaelsen, L.K. (1993) Cultural Diversities Impact on Integration Process and Performance: Comparing Homogeneous and Disease Task Groups. Academy Management Journal, 36, 590-602. http://dx.doi.org/10.2307/256593

[68] Thomas, D.C. and Kerr, I. (2009) Cultural Intelligence: People Skills for Global Business. Berrett-Koehler Publishers, San Francisco, 65-75.

[69] Thomas, D.C. (2006) Domain and Development of Cultural Intelligence: The Importance of Mindfulness. Group and Organization Management, 31, 78-99. http://dx.doi.org/10.2307/256593

[70] Grisham, T.W. and Derek, H.T. (2008) Gross-Cultural Leadership. International Journal of Managing Projects in Business, 1, 439-445. http://dx.doi.org/10.1108/17538370810883873

[71] Rahimnia, F., Mortazavi, S. and Delaram, T. (2010) A Survey of Cultural Quotient Influence on Functional Performance of Managers. Journal of Tomorrow Management, 8, 67-78. (In Persian)

[72] Parhizgari, J. (2000) A Survey of Relationship between Cultural Intelligence with Effectiveness and Conflict Management Style among Uromiah University of Managers. MSc. Dissertation in Management, Uromiah University, Uromiah. (In Persian)

[73] Abzari, M., Etebarian, A. and Khani, A. (2011) Influence of Cultural Intelligence on Group Effectiveness: Case of Mobarakeh Steel Company. Transformational Management Journal, 2, 30-33. (In Persian)

[74] Moshabaki, A. and Tizro, A. (2009) Influence of Emotional Quotient and Cultural Quotient on Leaders Success in Global Grade. Journal of Management Research in Iran, 2, 3-5. (In Persian)

[75] Taslimi, M.S., Gholipour, A. and Aleagha, M. (2009) The Ways for Improvement of Cultural Quotient of Governmental Managers about International Affairs. Journal of Management Research in Iran, 2, 29-57. (In Persian)

[76] Fayazi, M. and Jan Nesar Ahmadi, H. (2006) Cultural Quotient as a Managers Need in Diversity Century. Monthly Journal of Tadbir, 172, 41-43. (In Persian)

[77] Moshabbaki, A. and Ramous, N. (2006) Cultural Quotient as Success Elixir for Global Business Mangers. Journal of Urban Economics and Management, 3, 107-126. (In Persian)

[78] Woocher, L. (2015) Special Report. Conflict Assessment and Intelligence Analysis. United States Institute of Peace. www.usip.org

[79] Baddeley, S. (1987) Owl, Fox, Donkey or Sheep: Political Skills for Managers. Management Learning, 18, 3-19. http://dx.doi.org/10.1177/135050768701800101

[80] Adams, S.M. and Zanzi, A. (2006) Developing Political Intelligence for Making Feasible Decisions. Journal of Management Development, 25, 350-367. http://dx.doi.org/10.1108/02621710610655828

[81] Asadi, M., Tabatabaee, S.S. and Khayat Moghadam, S. (2014) The Survey of Relationship between Organizational Intelligence with Performance Indicators of Selected Hospitals in Mashhad University of Medical Sciences. Journal of Hospital, 13, 89-98. (In Persian) 